\title{
The Degree In Tourism At University Of Extremadura: Are Its Specific Competencies Being Highly Valued By Firms And Professionals? \\ Francisco Javier Ortega-Rossell, University of Extremadura, Spain Esteban Pérez-Calderón, University of Extremadura, Spain \\ Patricia Milanés-Montero, University of Extremadura, Spain
}

\begin{abstract}
In 2008, the University of Extremadura adapted their degrees in tourism in order to offer from the academic year 2009-2010 a full education in this area within which students can receive the European Higher Education Area (EHEA) Degree in Tourism.

The current framework for higher education, characterised by a more open offering, has, as its main aim, a greater rapprochement of the competencies and skills achieved by students and those that are demanded by the labor market and society in general. Because of this, the paper examines whether these new degrees will provide the expected results. The methodology used consists of a questionnaire distributed among the main institutions and professionals from Extremadura about specific competencies of Tourism studies.
\end{abstract}

Keywords: EHEA; Tourism; Competencies; Labor Market

\section{INTRODUCTION}

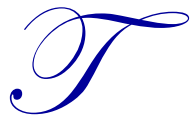

he reform of the European Higher Education Area (EHEA) within the Bologna Process is a challenge for Spanish universities, especially for a young university with very limited resources such as the University of Extremadura (UEx). But, it is also a process full of opportunities and advantages both for students and the university itself. The new working approach designed to homogenise higher education across Europe involves a sharp change in educational culture for students and teachers and it requires the adaptation of syllabi, infrastructure, and relations between the university and society.

As to the need for this reform and with reference to the specialist field - Business and Tourism Resource Management and Administration, the need was more than evident. There was a mismatch between the competencies required in the profession and those acquired by students in the educational process at the university. Accordingly, in this view, the current process of change regarding transparency, greater quality control, and monitoring in the teaching offered and the methods used will ensure that future graduates have the knowledge, competencies, abilities, and skills required to meet the educational demands of society, in general, and of tourism firms and organisations, in particular. This paper provides empirical evidence to support this thesis.

Regarding the organisation of the paper, the authors first analyse the theoretical framework and, second, they describe the empirical research objective, the used method, and the found results. To sum up, they present the conclusions. 


\section{THEORETICAL FRAMEWORK}

The adaptation and implementation of degree courses in the new area involves a thorough structural and methodological reform with regard to what is to be taught and what is to be learned. Thus, undergraduates need to acquire competencies through the performance of a range of activities related to certain specific contents, and these competencies are at the heart of the design of the degree course syllabus. The concept of competencies has multiple connotations, but in the context of Bologna, it refers to a combination of knowledge, aptitudes, skills, and responsibilities as required to perform suitably in a particular professional field (González \& Wagenaar, 2003; Escobar \& Jiménez, 2009).

The competencies specified for the Degree in Tourism course are several and various - Basic Specific Competencies, Generic Instrumental Competencies, Generic Personal Competencies, Generic Systemic Competencies, Specific Applied Competencies, Specific Degree in Tourism Competencies, Generic Transferable Competencies, and Specific Transferable Competencies. This paper focuses on the Specific Degree in Tourism Competencies which are shown in Table 1.

Table 1: Detail Of Specific Competencies

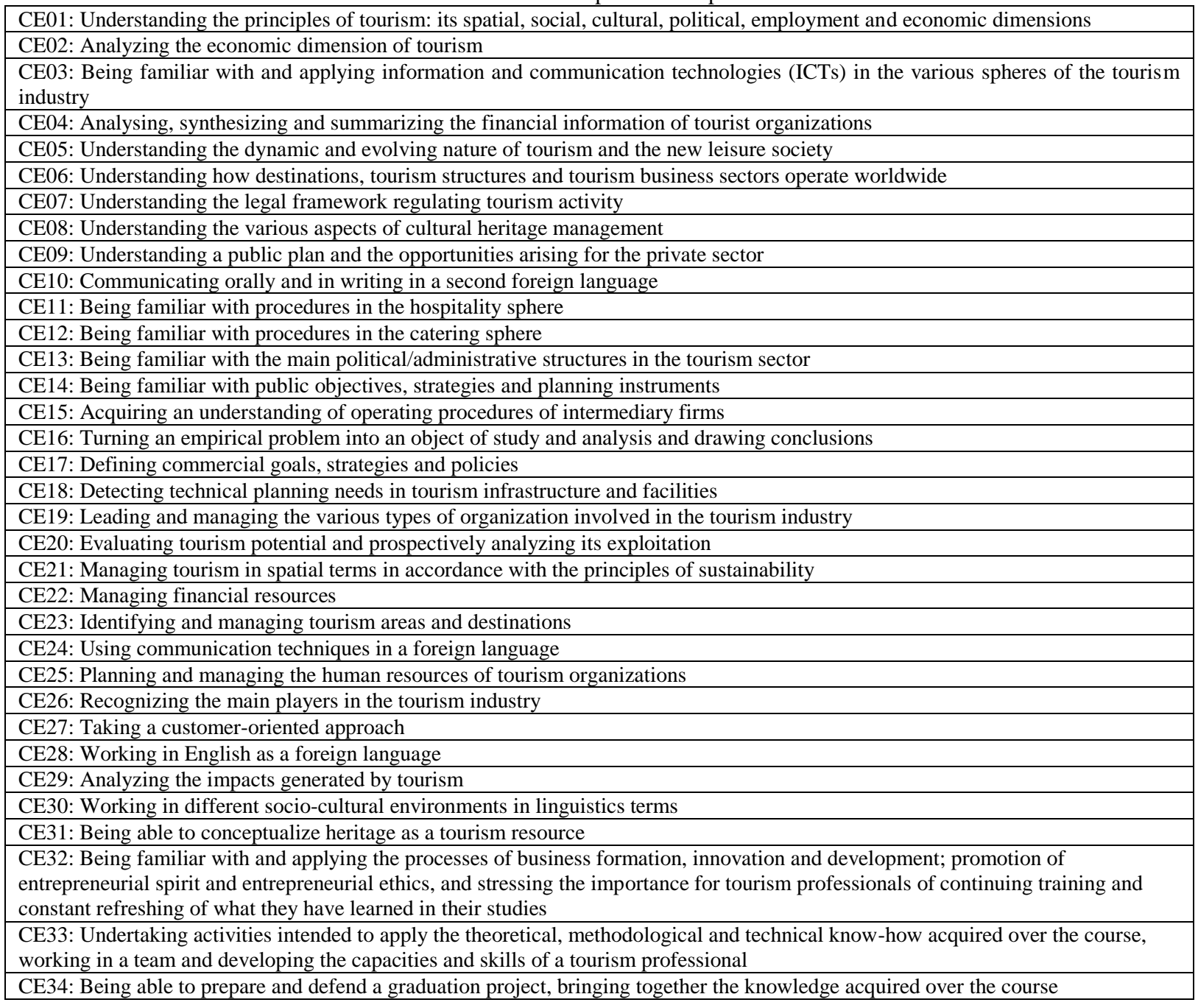




\section{METHOD AND RESULTS}

Regarding the objective of this study, taking into account the previous theoretical framework, this paper analysed the importance of labour market attributes to specific competencies of the Degree in Tourism designed by the Faculty of Business and Tourism Studies (FBTS) from the UEx (Spain). Therefore, the authors' empirical aim consists of stating in which way these competencies are being highly valued by firms and professionals from Extremadura. The obtained results will show if the designed degree complies with the EHEA objectives.

With reference to the used sample, the authors have focused their study on Caceres, which is one of the two provinces of Extremadura. The reason for this is because, in spite of in Extremadura, tourism isn't one of the key sectors of its economy (as happens in other communities in the interior); its Cultural Patrimony makes tourists visit it more and more. In 2010, it was visited by more than five million tourists (Source: Tourism Studies Institute). The old town of Caceres was declared the third Monumental Site in Europe in 1968 and UNESCO 'City of Human Patrimony' in 1986.

In relation to the method used, given the objective of this study, the authors designed a questionnaire to be distributed among the main entities that constitute the labour market of Extremadura. The competencies detailed in Table 1 formed the basis for elaborating the item batteries used in the questionnaire in which the authors asked about specific competencies by means of the question: Do you consider that competencies of the Degree of Tourism at UEx have a high value for students to join the workforce? (10: I fully agree, 1 = I do not agree).

Table 2 shows the sample of entities that answered the questionnaire, which constitutes $30 \%$ of the whole population of entities that have an agreement with the FBTS from the UEx.

Table 2: Sample Of Firms By Categories

\begin{tabular}{|l|c|c|}
\hline & Frequency & Percentage \\
\hline Public entities & 11 & 28,2 \\
\hline Private firms & 28 & 71,8 \\
\hline Total & 39 & 100,0 \\
\hline
\end{tabular}

The statistical technique applied to the data was cluster analysis (Ward's agglomerative hierarchical method and the non-hierarchical K-means [quick cluster] method) so as to seek to identify various positions in relation to the competencies of the degree across the Extremaduran labour market. The authors also used Logistic Regression to analyse the influence of those positions on the different categories of entities that constitute the labour market.

The most valued competencies are those related to the application of information and communication technologies (ICTs) in the various spheres of the tourism industry (CE03) and the use of communication techniques in a foreign language (CE10, CE24). The less valued competency is related to the analysis of the financial information of tourist organisations (CEC4). It might be due to the fact that touristic entities hire specialised accounting companies when they are small or have their own accounting departments when they are big. The Degree in Tourism at UEx includes a subject about financial accounting inside the module of Basic Formation and another one inside the module of Administration of Organizations and Enterprises.

The results of cluster analysis (see Table 3) show the existence of two categories of clusters that may be distinguished according to how touristic public and private entities of Extremadura valuate the competencies of the Degree in Tourism - medium (C1) and high (C2) - made up of 10 and 27 entities, respectively. If one focuses on the variables that are significant in the sets, the main differences between the clusters are as shown in Table 4.

\section{Cluster 1}

This cluster includes 10 touristic entities which give a bit less value to specific competencies of the degree. The better-valued competencies are related to the use of ICTs, understanding the principles of tourism, and the new leisure society. 


\section{Cluster 2}

This is a cluster of 27 touristic entities which give the specific competencies the highest value. The specific competencies with higher value are those related to communicating orally and in writing in a second language and using communication techniques in a second language, too.

Table 3: Number Of Cases By Each Cluster

\begin{tabular}{|l|c|c|}
\hline Clusters & $\mathbf{1}$ & 10.000 \\
\hline & $\mathbf{2}$ & 27.000 \\
\hline Valids & & 37.000 \\
\hline Lost & 2.000 \\
\hline
\end{tabular}

Table 4: ANOVA

\begin{tabular}{|c|c|c|c|c|c|c|c|c|}
\hline & \multicolumn{2}{|c|}{ Final Clusters Center } & \multicolumn{2}{|c|}{ Clusters } & \multicolumn{2}{|c|}{ Error } & \multirow[b]{2}{*}{$\mathbf{F}$} & \multirow[b]{2}{*}{ Sig } \\
\hline & 1 & 2 & $\begin{array}{c}\text { Mean } \\
\text { Square }\end{array}$ & DF & $\begin{array}{c}\text { Mean } \\
\text { Square }\end{array}$ & DF & & \\
\hline CE01 & 5.70 & 6.07 & 1.021 & 1 & 1.541 & 35 & .662 & .421 \\
\hline CE02 & 5.30 & 6.00 & 3.576 & 1 & 1.660 & 35 & 2.154 & .151 \\
\hline CE03 & 5.50 & 6.70 & 10.573 & 1 & .632 & 35 & 16.722 & .000 \\
\hline CE04 & 4.20 & 5.19 & 7.083 & 1 & .905 & 35 & 7.826 & .008 \\
\hline CE05 & 5.60 & 6.26 & 3.172 & 1 & .560 & 35 & 5.668 & .023 \\
\hline CE06 & 5.50 & 5.96 & 1.564 & 1 & .842 & 35 & 1.858 & .182 \\
\hline CE07 & 5.40 & 6.15 & 4.084 & 1 & .794 & 35 & 5.141 & .030 \\
\hline CE08 & 4.80 & 5.81 & 7.515 & 1 & .848 & 35 & 8.864 & .005 \\
\hline CE09 & 4.70 & 5.81 & 9.069 & 1 & .805 & 35 & 11.266 & .002 \\
\hline CE10 & 5.50 & 6.85 & 13.336 & 1 & .797 & 35 & 16.725 & .000 \\
\hline CE11 & 5.20 & 6.19 & 7.083 & 1 & 1.019 & 35 & 6.949 & .012 \\
\hline CE12 & 4.80 & 6.07 & 11.845 & 1 & .899 & 35 & 13.182 & .001 \\
\hline CE13 & 4.80 & 5.52 & 3.767 & 1 & .695 & 35 & 5.417 & .026 \\
\hline CE14 & 4.40 & 5.89 & 16.177 & 1 & .945 & 35 & 17.122 & .000 \\
\hline CE15 & 4.40 & 5.85 & 15.382 & 1 & .852 & 35 & 18.061 & .000 \\
\hline CE16 & 3.90 & 5.78 & 25.731 & 1 & .959 & 35 & 26.829 & .000 \\
\hline CE17 & 4.90 & 6.48 & 18.251 & 1 & .675 & 35 & 27.021 & .000 \\
\hline CE18 & 5.10 & 6.15 & 8.017 & 1 & 1.094 & 35 & 7.325 & .010 \\
\hline CE19 & 4.70 & 6.33 & 19.468 & 1 & .689 & 35 & 28.272 & .000 \\
\hline CE20 & 4.70 & 6.00 & 12.332 & 1 & .689 & 35 & 17.910 & .000 \\
\hline CE21 & 4.50 & 6.33 & 24.527 & 1 & .871 & 35 & 28.146 & .000 \\
\hline CE22 & 4.80 & 6.30 & 16.338 & 1 & .778 & 35 & 21.000 & .000 \\
\hline CE23 & 5.10 & 6.26 & 9.807 & 1 & .631 & 35 & 15.541 & .000 \\
\hline CE24 & 5.10 & 6.85 & 22.395 & 1 & .866 & 35 & 25.863 & .000 \\
\hline CE25 & 4.30 & 6.33 & 30.170 & 1 & .689 & 35 & 43.816 & .000 \\
\hline CE26 & 5.10 & 6.11 & 7.460 & 1 & .788 & 35 & 9.472 & .004 \\
\hline CE27 & 5.00 & 6.70 & 21.181 & 1 & .904 & 35 & 23.438 & .000 \\
\hline CE28 & 4.90 & 6.74 & 24.726 & 1 & .860 & 35 & 28.765 & .000 \\
\hline CE29 & 4.80 & 5.93 & 9.251 & 1 & .556 & 35 & 16.645 & .000 \\
\hline CE30 & 3.70 & 5.70 & 29.297 & 1 & .735 & 35 & 39.853 & .000 \\
\hline CE31 & 4.00 & 6.04 & 30.280 & 1 & .656 & 35 & 46.153 & .000 \\
\hline CE32 & 4.60 & 6.26 & 20.090 & 1 & .902 & 35 & 22.263 & .000 \\
\hline CE33 & 4.90 & 6.44 & 17.406 & 1 & 1.130 & 35 & 15.397 & .000 \\
\hline
\end{tabular}

In order to know if the kind of touristic entity (public or private) determines its belonging to one cluster or another, the authors use the variable "category" whose value is 0 when the touristic entity is a public entity and 1 when it is a private firm of the touristic service industry. In Cluster 1, 10\% of the entities are public entities and $90 \%$ are private firms. Nevertheless, in Cluster 2, 37\% are public entities and $63 \%$ are private firms. The methodology used is a logistic regression that lets one predict the probability of occurrence of each situation. 
Table 5 shows the resume of the Logit model proposed for each regression. As can be seen, with 70,3\% of cases correctly classified in both Logit models, the variable category is only statistically significant at the $86 \%$ level. Nevertheless, the fact that this variable has been significant in both Logit and with a great power differentiator brings consistency to the clusters.

Table 5: Resume Of Logit Model

\begin{tabular}{|c|c|c|c|c|c|c|}
\hline \multirow{3}{*}{ Explanatory Variables } & \multicolumn{6}{|c|}{ Dependent Variables } \\
\hline & \multicolumn{3}{|c|}{$\begin{array}{c}\text { C1 (Entities That Valuate Less The } \\
\text { Competencies) }\end{array}$} & \multicolumn{3}{|c|}{$\begin{array}{c}\text { C2 (Entities That Valuate More The } \\
\text { Competencies) }\end{array}$} \\
\hline & $\beta$ & Sig. & $\operatorname{Exp}(\beta)$ & $\beta$ & Sig. & $\operatorname{Exp}(\beta)$ \\
\hline \multirow[t]{2}{*}{ Category } & 1,667 & 0,139 & 5,294 & $-1,667$ & 0,139 &, 189 \\
\hline & \multicolumn{3}{|c|}{ \% De Clasificación: 70,3\% } & \multicolumn{3}{|c|}{ \% De Clasificación: 70,3\% } \\
\hline
\end{tabular}

$\mathrm{C} 1=\beta 1$ (Category) $\mathrm{C} 2=\beta 1$ (Category)

At the $86 \%$ level, there is a probability of $70.3 \%$ that a public touristic entity from Caceres gives the competencies of the Degree in Tourism a higher value instead of a lower one. Table 3 shows that Cluster 1 consists of $10 \%$ public entities and the Cluster 2 consists of $37 \%$.

The reason why the vast majority of public entities related to the tourism industry in Caceres belong to the cluster that gives a higher value to the specific competencies of the Degree might be because these competencies related to tourism are always necessary for a graduate who wants to work in a public entity. Nevertheless, in the case of private firms in the tourism service industry, this necessity isn't always so strong. This could be due to the fact that a larger number of these firms are small hotels or restaurants which don't need so many highly qualified staff.

\section{CONCLUSIONS}

Globalisation is one of the basic characteristics of our days, which has extended to all fields, including the educational and the university ones. Universities and Centers are called to compete for students and resources and to innovate to attract the best teaching resources, encouraging the mobility of students, teachers, administrative staff, and services. Competitiveness between the different educational institutions and the globalisation of the educational process are the factors that promote the need to attract students, as well as to bring the skills, abilities, and attitudes of graduates closer to the professional demands formalised by corporations, business, and society in general.

The FBTS has redesigned and adapted the Diploma in Tourism of the EHEA by placing the student at the center of this reform, combining training and knowledge related to the administration and organisation of tourism resources with the learning of skills, abilities, and attitudes of an expert tour manager or manager in order that graduates in Tourism successfully conduct professional performance and gain access with credit and recognition to the labour market.

The empirical study developed shows that the specific competencies of the Degree in Tourism are being highly valued by firms and professionals of Extremadura. Therefore, it seems to be that the designed degree complies with EHEA objectives. This fact is even clearer in the case of touristic public entities.

The fact that graduates must be well aware of both the technical expertise tasks and the responsibilities that should come to play in the future, and that they should come to assume, is of fundamental importance. The training has to show the students that the Degree in Tourism is not an end, but a means to materialise as people, as professionals who contribute to the improvement and progress of our society.

\section{AUTHOR INFORMATION}

Francisco Javier Ortega-Rossell, Ph.D., is a Professor at the Faculty of Business Studies and Tourism of the Universidad of Extremadura. He is an Auditor Member Accounts and Auditors Institute of Chartered Accountants of Spain and registered in the Official Register of Auditors (ROAC). He has been Dean of the Faculty of Business 
Studies and Tourism University of Extremadura during the years 2008-2012. Email: jortega@ unex.es.

Esteban Pérez-Calderón, Ph.D., (contact author) is an Associate Professor at the Faculty of Business Studies and Tourism of the Universidad of Extremadura. He is the author of several studies on the European Higher Education and is a member of Quality Committee responsible for the Degree of Business Administration in the Faculty of Business Studies and Tourism. Email: estperez@unex.es.

Patricia Milanés-Montero, Ph.D., is an Associate Professor at the Faculty of Economics of the Universidad of Extremadura. She is currently Vice-Dean for inter-university relations in this Faculty and is the author of several studies on the European Higher Education. Email: pmilanes@unex.es.

\section{REFERENCES}

1. Escobar, B., y Jiménez, S. (2009). La implantación del Grado en Finanzas y Contabilidad en el contexto del Espacio Europeo de Educación Superior: el caso de la Universidad de Sevilla. Revista Española de Financiación y Contabilidad, 38(142), 293-310.

2. González, J. y Wagennar, R. (2003). Tuning educational structures in Europe. Final Report. Pilot Project v.1. ANECA, Madrid. 